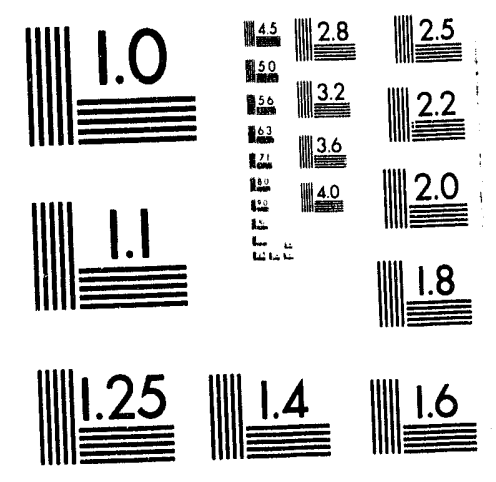



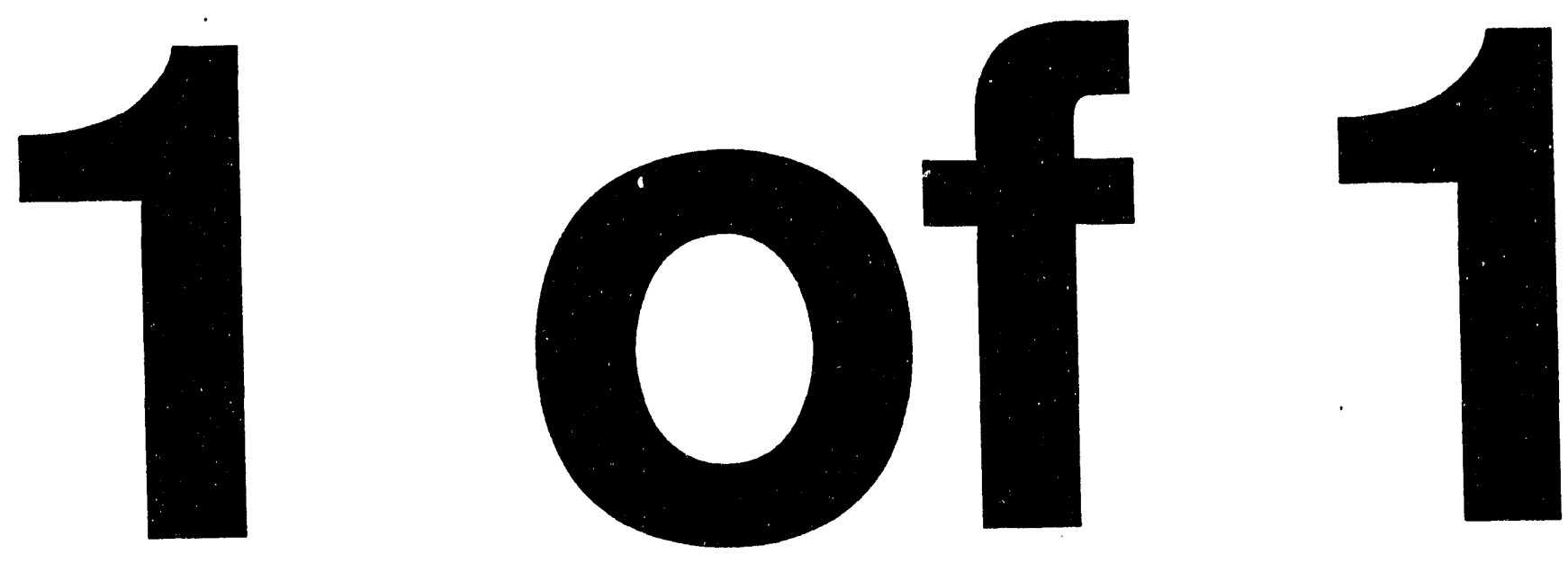


\section{Conf $-931054--10$}

UCRL-JC-114997

PREPRINT

\section{A Historical Perspective on Fifteen Years of Laser Damage Thresholds at LLNL}

F. Rainer, F. P. De Marco, M. C. Staggs,

M. R. Kozlowski, L. J. Atherton, L. M. Sheehan

This paper was prepared for submittal to the 1993 Boulder Damage Symposium

Boulder, $\mathrm{CO}$

October 27-29, 1993

December 21, 1993

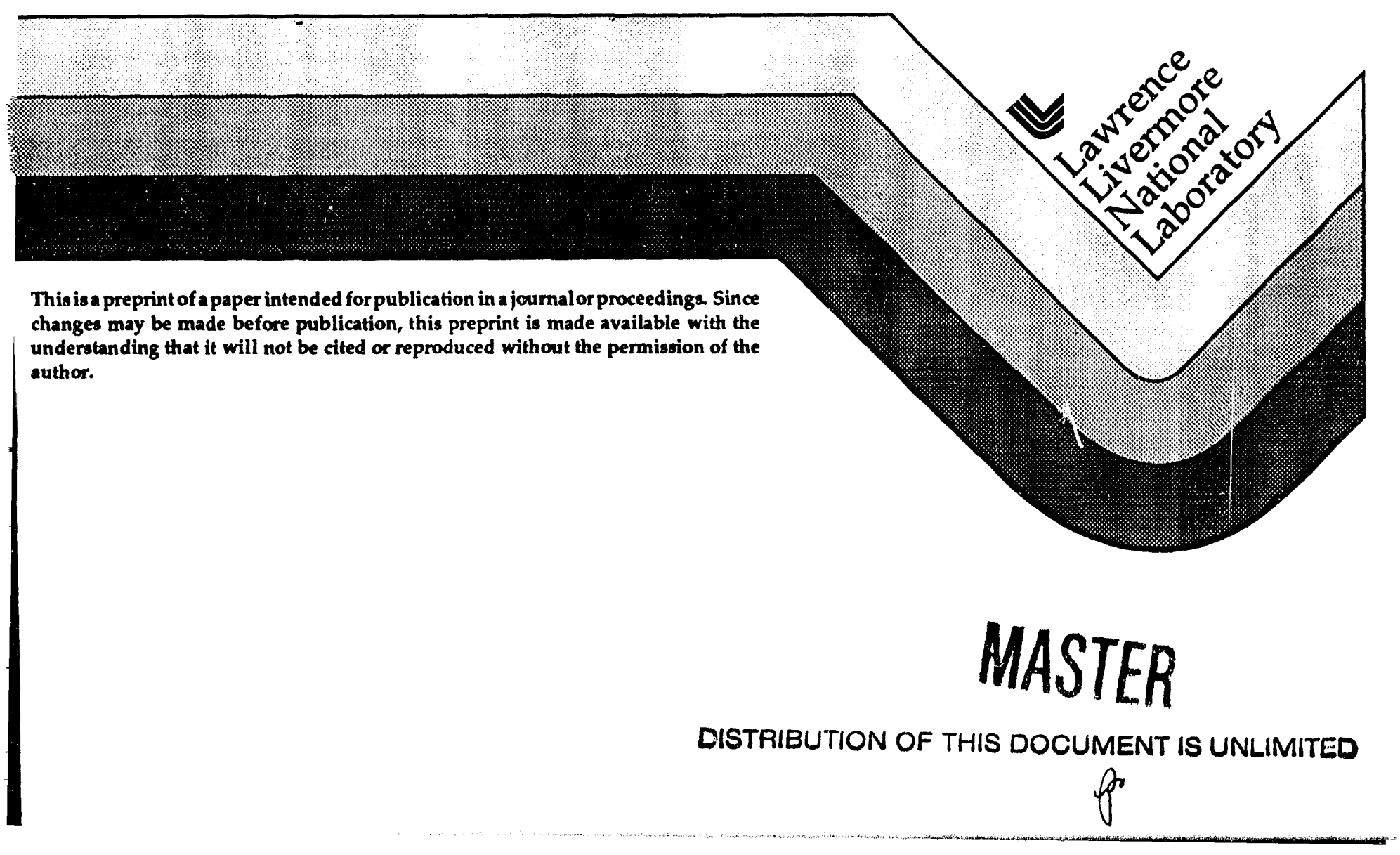


DISCLAIMER

This document was prepared es en account of work sponsored by an agency of the United Stales Government. Neither the United States Government nor the Univervity of California nor any of their employees, makes any warrenty, expreas or bmplied, or

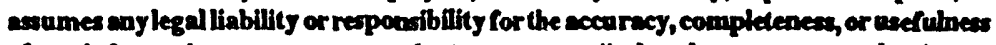
of any information, apparalus, product, or process disclosed, or represents that its use would not infringe privately owned rights. Reference herein to any specific commerctal products, process, or service by trade name, trademark, manuf scturer, or otherwise, does not necessarily constitute or imply its endorsement, recommendation, or favoring by the United States Government or the University of California. The views and opinions of authors expreased herein do not necessarily state or reflect those of the United States Government or the Univerrity of Celifomia, and shall not be used for advertising or product endorsement purposea. 


\title{
A historical perspective on fifteen years of laser damage thresholds at LLNL
}

\author{
F. Rainer, F. P. De Marco, M. C. Staggs, \\ M. R. Kozlowski, L. J. Atherton, and L. M. Sheehan \\ Lawrence Livermore National Laboratory \\ P. O. Box $5508, \mathrm{~L}-490$ \\ Livermore, CA $94551-9900$
}

\begin{abstract}
We have completed a fifteen-year, referenced and documented compilation of more than 15,000 measurements of laser-induced damage thresholds (LIDT) conducted at the Lawrence Livermore National Laboratory (LLNL). These measurements cover the spectrum from 248 to $1064 \mathrm{~nm}$ with pulse durations ranging from $<1 \mathrm{~ns}$ to $65 \mathrm{~ns}$ and at pulse-repetition frequencies (PRF) from single shots to $6.3 \mathrm{kHz}$.

We emphasize the changes in LIDTs during the past two years since we last summarized our database. We relate these results to earlier data concentrating on improvements in processing methods, materials, and conditioning techniques. In particular, we highlight the current status of anti-reflective (AR) coatings, high reflectors (HR), polarizers, and frequency-conversion crystals used primarily at $355 \mathrm{~nm}$ and $1064 \mathrm{~nm}$.
\end{abstract}

\section{INTRODUCTION}

On a biennial basis we have in recent years published in these proceedings database summaries of LIDTs measured at LLNL: 1, 2,3 These summaries, as well as many ancillary publications, have documented the development of high-threshold optical components for use in large-scale laser systems employed in the research of inertial confinement fusion (ICF). These progressively more powerful laser systems have included: Long Path (1970), Janus (1974), Cyclops (1975), Argus (1976), Shiva (1977), Novette (1982), Nova (1984), Beamlet (1994), and the proposed National Ignition Facility (NIF). The development of high-threshold optical components for these systems involved extensive collaborative efforts between LLNL and many commercial vendors, universities and laboratories both foreign and domestic. A partial list of these is shown in Table. 1.

We are engaged in an effort to ultimately publish a non-proprietary version of this database which will cover the spectrum from $248 \mathrm{~nm}$ to $1064 \mathrm{~nm}$ with pulse durations ranging from $<1 \mathrm{~ns}$ to $84 \mathrm{~ns}$. We shall highlight here some of the more crucial elements in ICF laser systems shown in bold in Table 2. We will provide a perspective on the development of damage thresholds for these components during the past 15 years with particular emphasis on current thresholds at $355 \mathrm{~nm}(3 \omega)$ and $1064 \mathrm{~nm}(1 \omega)$ measured during the past two years. In order to provide a common footing for thresholds measured at a variety of pulse durations, we will present these results in terms of 3-ns values, scaled by appropriate, empirically-determined scaling factors. More extensive details of materials used in each of the categories may be found in reference 3. Generic descriptions of our damage test facilities and capabilities can be found in reference 4.

We have conducted damage tests with PRFs ranging from single shots up to $6.3 \mathrm{kHz}$. Most of our recent tests have been conducted at a PRF of $10 \mathrm{~Hz}$. Evidence of threshold enhancement has been demonstrated at these proceedings over the last few years utilizing conditioning irradiation in which the sample is irradiated by gradually increasing fluences. Fig. 1 displays the different methods of test irradiations which are specified in our database for

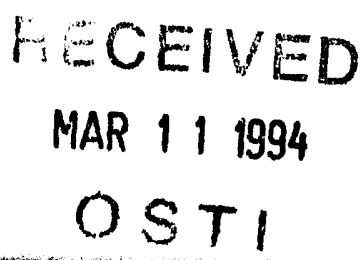


$-2-$

\begin{tabular}{|l|l|l|l|l|}
\hline Acton & Deposition Sciences & Inrad & NSG & SPAWR \\
AFWL & Desag & Intermedics & NWC & Spindler \&c Hoyer \\
Airtron & Design Optics & Itek & OCLI & Stanford (U) \\
Alfred (U) & Diamonex & Japan & OI & TecOptics \\
Allied & DuPont & Kigre & Optico Glass & Thin Film Coat \\
American Thermal & Dynasil & Kirtland & Optics Plus & Tinsley \\
Applied Optics & Echantillon & Kodak & OptiFab & Toshiba \\
Arizona (U) & Edmund & Labsphere & Optochemical & Trans World Opt. \\
AT\&T & Epner Technology & Lambda Airtron & Optovac & Ukraine (ISC) \\
Aurel & Epoxy Technology & Lambrecht & Oriel & Ultramet \\
AWRE & ERIM & Lasermetrics & Osaka (U) & Unertl \\
Balzers & Feroxcube & Laser Optics & Pacific Optical & Union Carbide \\
Battelle Columbus & Fish-Schurman & Laser Power Optics & Pacific West S. & United Lens \\
Battelle PNL & France & Lensbond & Perkin Elmer & US Paint \\
Bond & Fujian & Lightning Optical & Phillips & USSR \\
Broomer & GE & PMS & UTOS \\
Burleigh & GEC & Limeil & Polycast & Virgo \\
Canon & Gentec & Litton & Polymer Corp & WDQ \\
Cascade Optical & Germany & LLNL & Quartz \& Silice & Westinghouse \\
CCI & Gesänger & Matra & Rochester (U) & Willis \\
Central Florida (U) & Glendale & Meller & Rocky Flats & Wisotzki \\
China & GM Assoc & MMM & Russia & ZC\&R \\
Coherent & Halocarbon & Moscow (U) & Russia (LAP) & Zygo \\
Continental & Harshaw & Mykroy & San Francisco (U) & \\
Corning & Heraeus & NBS & Schott & \\
Crystal Technology & Honeywell & New Mexico (U) & Scientific Coating & \\
CVD & Hoya & Newport & Shandonz & \\
CVI & Hughes & Norland & Shanghai & \\
Davis (U) & Hyperfine & Northrop & Showa & \\
Deacon & IBM & NRL & Spectra-Physics & \\
\hline
\end{tabular}

Table 1. Partial list of commercial vendors, universities, laboratories, and countries that have contributed to the development of high-threshold optical materials for LLNL.

\begin{tabular}{l|l}
\hline Coatings & $\begin{array}{l}\text { ANTI-RELECTIVE (AR), HIGHLY REFLECTIVE (HR), POLARIZERS, single and mul- } \\
\text { tiple layers } \\
\text { surface and bulk thresholds for the above elements, lenses, optical rotators and waveplates, } \\
\text { Substrates }\end{array}$ \\
$\begin{array}{l}\text { laser glasses, filters } \\
\text { surface and bulk thresholds for FREQUENCY CONVERSION, laser hosts } \\
\text { Gratings } \\
\text { reflective, transmissive } \\
\text { Metals }\end{array}$ & $\begin{array}{l}\text { bare metals, overcoated metals } \\
\text { Miscellaneous }\end{array}$ \\
\hline
\end{tabular}

Table 2. Types of components tested for laser induced damage thresholds at LLNL. 
frequency conversion crystals. The methods on the right indicate situations under which thresholds may be improved (including pre-irradiation thermal annealing). Our current primary irradiation methods for conducting damage tests are at $10 \mathrm{~Hz}$ with 600 shots of the same fluence $(S / 1)$, or 600 shots of ramped-up fluence $(R / 1)$.
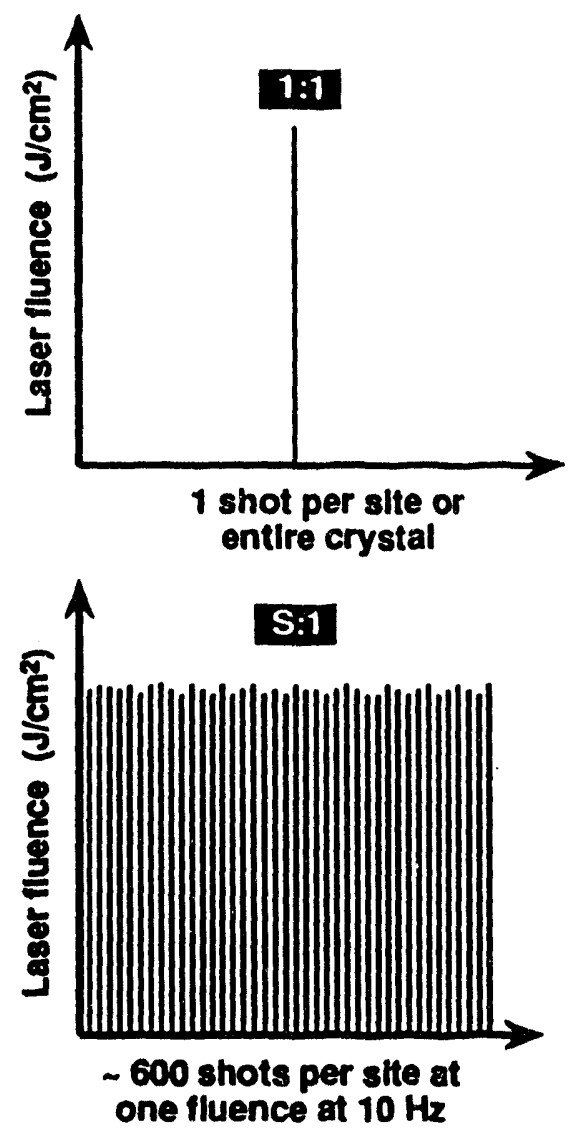

No conditioning

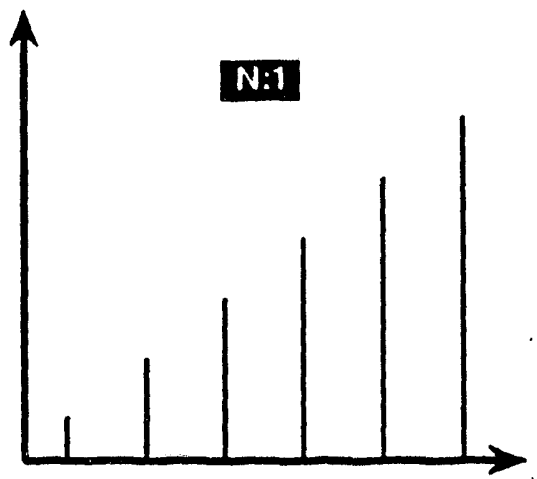

$N$ discrete increasing-fluence shots per stte or entire crystal

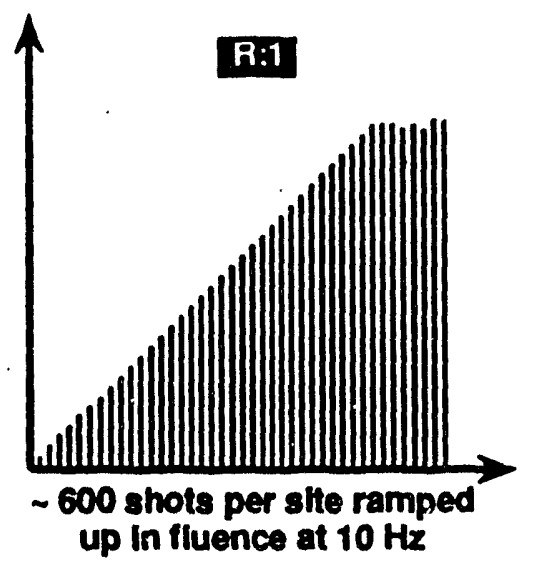

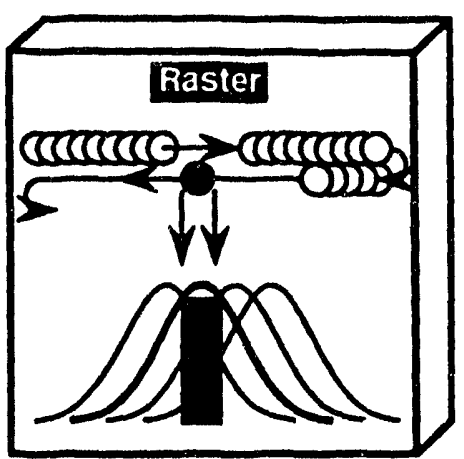

Laser raster scan entire crystal with small beam

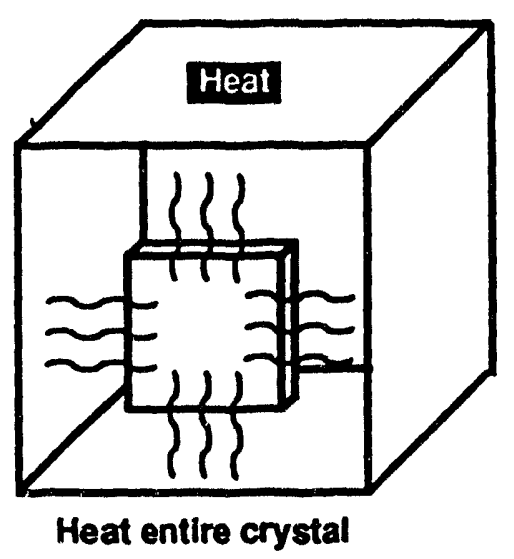

Fig. 1. Definitions of the different types of irradiation and conditioning methods (in this case for KDP crystals).

\section{OPTICAL COMPONENTS}

\subsection{Anti-reflective (AR) coatings}

Fig. 2 summarizes the results of all damage tests that we have conducted at $1 \omega$ on AR coatings. In this, as well as in subsequent figures, small circles will represent unconditioned irradiations (usually $1 / 1$ in the early years, $S / 1$ in the later years); large circles imply conditioning by $N / 1, R / 1$ or rastered irradiation. However, the figure does not show a one-on-one comparison of conditioned vs. unconditioned thresholds for specific samples. We conducted most of our recent tests with conditioned irradiation which typically provided a small amount of threshold improvement. This was probably due to cleaning and expulsion of volatile solvents. However, we seldom observed improvement by factors of two or three that has been common with HRs and polarizers (see below). Fig. 3 shows a corresponding, but smaller, database of such tests conducted at $3 \omega$. The $3 \omega$ work lagged a few years behind that at $1 \omega$ and for a while waned as our testing capabilities changed. The legends in each case specify the ranges of pulse durations used in the 
tests. In order to facilitate comparison of the development of damage thresholds over wide ranges of pulse durations for thousands of tests, we have scaled all the thresholds to 3 -ns values by a scaling factor of $t^{0.35}$. This is an empirically derived factor and varies some between AR, HR, and polarizer coatings. Our efforts followed two separate paths.

In the early years (1978 to 1983) of our research in high-threshold optical coatings, we exerted our greatest efforts in trying to develop acceptable AR coatings for use at $1 \omega$. At that time these proved to be the most damage-prone elements in high-fluence laser chains. The conventional method employed multi-layer, alternate coatings deposited by e-beam evaporation. These typically consisted of a combination of a high-index-of-refraction material and silica. During those years we have presented at these proceedings the results of improvements in laser damage thresholds employing one or more of the following techniques: choice of substrates ${ }^{5}$, choice of high-index material ${ }^{5,6}$, half-wavethick undercoats of silica (or another low-index material) between the AR stack and the substrate (barrier layer) ${ }^{6,7}$. deposition parameters (temperature, $\mathrm{O}_{2}$ pressure, deposition rate), and modified layer designs (layer thickness, layer numbers) ${ }^{6}$. The average annual improvement in thresholds by these techniques ranged on the order of only 10 to $15 \%$. Histograms of the choice material combinations for such e-beam deposited coatings are shown in reference 3 for wavelengths ranging from $1064 \mathrm{~nm}$ to $248 \mathrm{~nm}$.

LLNL, in conjunction with commercial and government liaboratories, also experimented with a variety of more exotic and often vendor-proprietary techniques to generate AR properties on assorted substrate types. We conducted damage tests on gradient-index films ${ }^{8}$, leached films, phase-separated glass, neutron-tracked glass, metalo-organicdeposited (MOD) films, liquid films, Schroeder-process films, neutral-solution coatings ${ }^{9}$, and solgel coatings ${ }^{10}$. Although it has not been practical to identify these types of AR coatings in Figs. 2 and 3, in general we found that many of the high-threshold samples stemmed from this latter set of processes. However, in most cases these technologies were not able to be extended to production optics. This was for a variety of reasons: the optical or damage properties were not uniform, the AR surfaces had high densities of defects, the processes could not be applied to large optics, the AR surfaces were very fragile, or the processes were very expensive.

Between 1984 and 1991 we concentrated almost exclusively on the solgel process, applied either by dip or spin coating. Our earlier endeavors did not necessarily yield thresholds as high as those of the better e-beam coatings, but careful attention to clean processing ultimately resulted in AR coatings having among the highest thresholds, rather than the lowest, for coated optical elements. ${ }^{11,12}$ The fragile nature of solgel proved not to be a significant problem. Coatings could in fact be spray cleaned in situ. ${ }^{13}$ If contaminated or damaged, the entire coating, often on the order of $1 \mathrm{~m}$ in size, could simply be wiped off and recoated. This would be at a cost of a few hundred dollars as opposed to tens of thousands of dollars required to polish off and recoat an e-beam-deposited AR. By the late 1980s we resumed $3 \omega$ coating fabrication and testing. These also ultimately had thresholds higher than other $3 \omega$ coated optics.

Most of our AR efforts in 1992 and 1993 concentrated on an assortment of experimental techniques which included ARs fabricated with a meniscus coater, including the use of sec-butanol as a suspension medium ${ }^{14}$, ammonia-treated solgels, dip-and thermally-evaporated Teflon ${ }^{15,16}$ and silicone coatings, the use of organic polymer bindings ${ }^{17}$, and the treatment of coating contamination in a hostile target-chamber environment. These tests were conducted at both $1 \omega$ and $3 \omega$ yielding a large spread in thresholds. The very high thresholds observed in 1990 werd not repeated. That was because those coatings represented the state-of-the-art, production coatings applied routinely on the optics used in the Nova laser facility. Most tests in 1992 and 1993 involved assorted experimental techniques which usually had somewhat lower thresholds. 
$-5-$

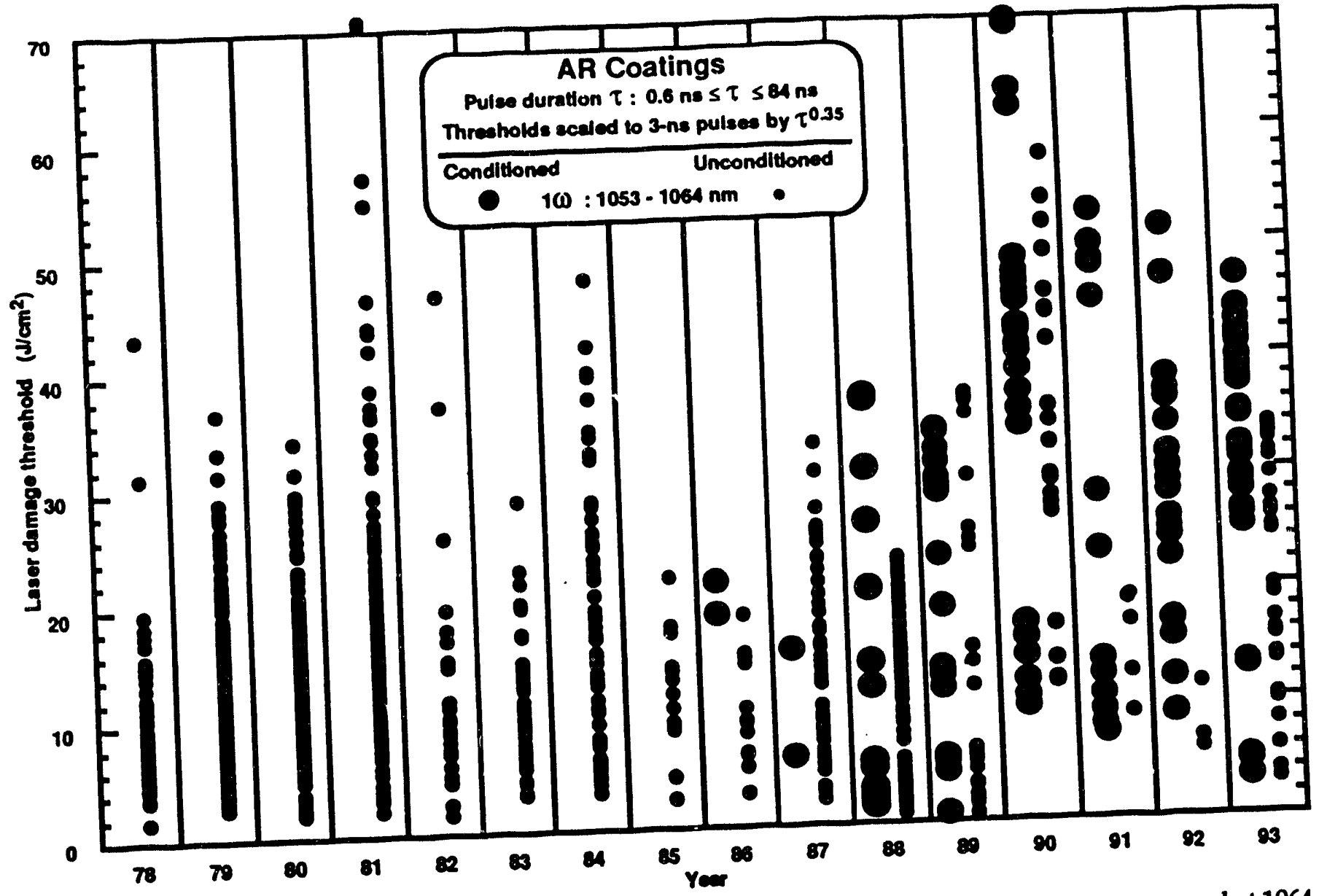

Fig. 2. Conditioned and unconditioned damage thresholds of all anti-reflective (AR) coatings measured at 1064 $\mathrm{nm}(1 \omega)$, scaled to 3 -ns values by $\tau^{035}$.

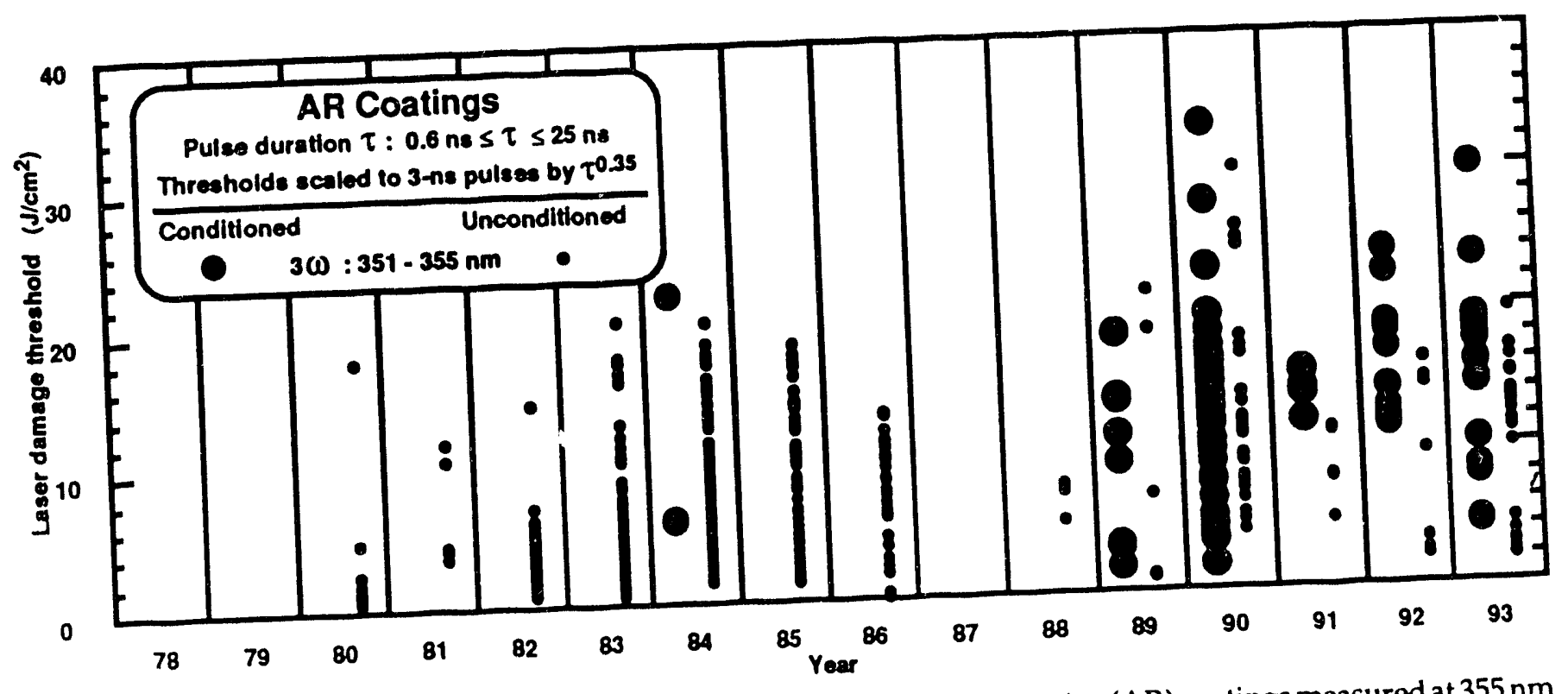

Fig. 3. Conditioned and unconditioned damage thresholds of all anti-reflective (AR) coatings measured at $355 \mathrm{~nm}$ $\left(3(\omega)\right.$ ), scaled to 3 -ns values by $\tau^{0.35}$. 
Figs. 4 and 5 show respectively all of our damage testing conducted on HR coatings at $1 \omega$ and $3 \omega$. The relationships of materials to damage thresholds at these and the other harmonics are again provided in detail in reference 3 . The same conments regarding conditioning and scaling of the thresholds to 3-ns values apply to $H R s$ as were noted for ARs.

All of the developmental work in high-threshold HR coatings between 1978 and 1986 was conducted with unconditioned irradiation (almost exclusively 1/1). In these years we worked primarily in collaboration with commercial vendors to fabricate multi-layer, e-beam-deposited coatings. To a lesser degree, and also with less success, we investigated sputtered and ion-assisted coatings. We conducted many of the same types of parameter variations mentioned for e-beam-deposited AR coatings. These included the choice of high-index material, multiple high-index materials, half-wave-thick overcoats of silica (or another low-index material) on top of the HR stack, deposition parameters (temperature, $\mathrm{O}_{2}$ pressure, deposition rate), and modified layer designs (layer thickness, layer numbers). $5,18,19$ Coating designs were also modified to provide desired multi-chroic optical characteristics at $1 \omega, 2 \omega$ and $3 \omega$. The fact that the earlier tests were conducted only with single pulses led to some erroneously high thresholds in coatings, particularly those made with titania. ${ }^{20}$ Single-shot damage in such HRs was often so subtle that it was imperceptible with $100 \times$ Nomarski microscopy. However, multiple shots subsequently led to the rapid growth of that subtle damage to readily visible proportions. This prompted us to concentrate more on materials such as tantala and hafnia at $1 \omega$ and scandia and various fluorides at $3 \omega .^{18}$

With construction of the Reptile damage facility in 1986, we conducted virtually all of our damage tests from 1986 to 1991 using rep-rated pulses ranging in PRFs from 10 to $120 \mathrm{~Hz}$. These proved to be effective "lifetime tests of the optics since a one-minuteirradiation on Reptile could actually represent a year or more of shots conducted with a Shiva or Nova laser. It was in this time span that we began to pursue conditioning of HRs as an offshoot of earlier KDP work. It turned out, that even in the late 1970s, we had observed that the bulk damage thresholds of KDP crystals could be raised by gradually increasing the fluences of the test laser pulses from very low levels (see below). ${ }^{21,22}$ With a single-shot laser this was a tedious, time-consuming operation. Using a rep-rated test laser we were able to conduct such irradiations with hundreds of shots of increasing fluences in just one minute rather than tens of shots in hours. The ramping was accomplished by varying the laser fluence with a remotely-controlled rotation of a waveplate. We designated this as $R / 1$ irradiation as compared to the earlier $N / 1$ irradiation of numerous single shots.

The improvements in damage thresholds by the conditioning of $1 \omega \mathrm{HR}$ coatings, particularly those made of hafnia/silica, was so promising that a great deal of effort was spent during the subsequent years. Our research showed that (1) the rise in thresholds typically ranged by factors of two to three, (2) was permanent over a time span of months, (3) could be accomplished to some degree by a few full-aperture shots of the Nova laser or by rastering with a small rep-rated laser. ${ }^{23,24}$ We established that the primary source for the onset of damage in the HRs stemmed from nodular defects deposited during the coating process. This prompted us to begin a study of such defects using Atomic Force Microscopy (AFM). ${ }^{25}$ Concurrent with the conditioning efforts of $\mathrm{HRs}$ fabricated by conventional e-beam deposition for immediate deployment on Nova, we also began to investigate some experimental techniques. Initial results of damage testing of multi-layer solgel HRs proved to yield only marginally acceptable thresholds. ${ }^{26}$ On the other hand, we experienced some of our highest thresholds by first depositing and repolishing thick dielectric layers on a substrate before the final HR stack was deposited. This was accomplished successfully on dielectric substrates, metal substrates and metal layers in support of LLNL's free-electron-laser program. 27

During 1992 and 1993 we continued to emphasize the AFM study of nodular coating defects and the 


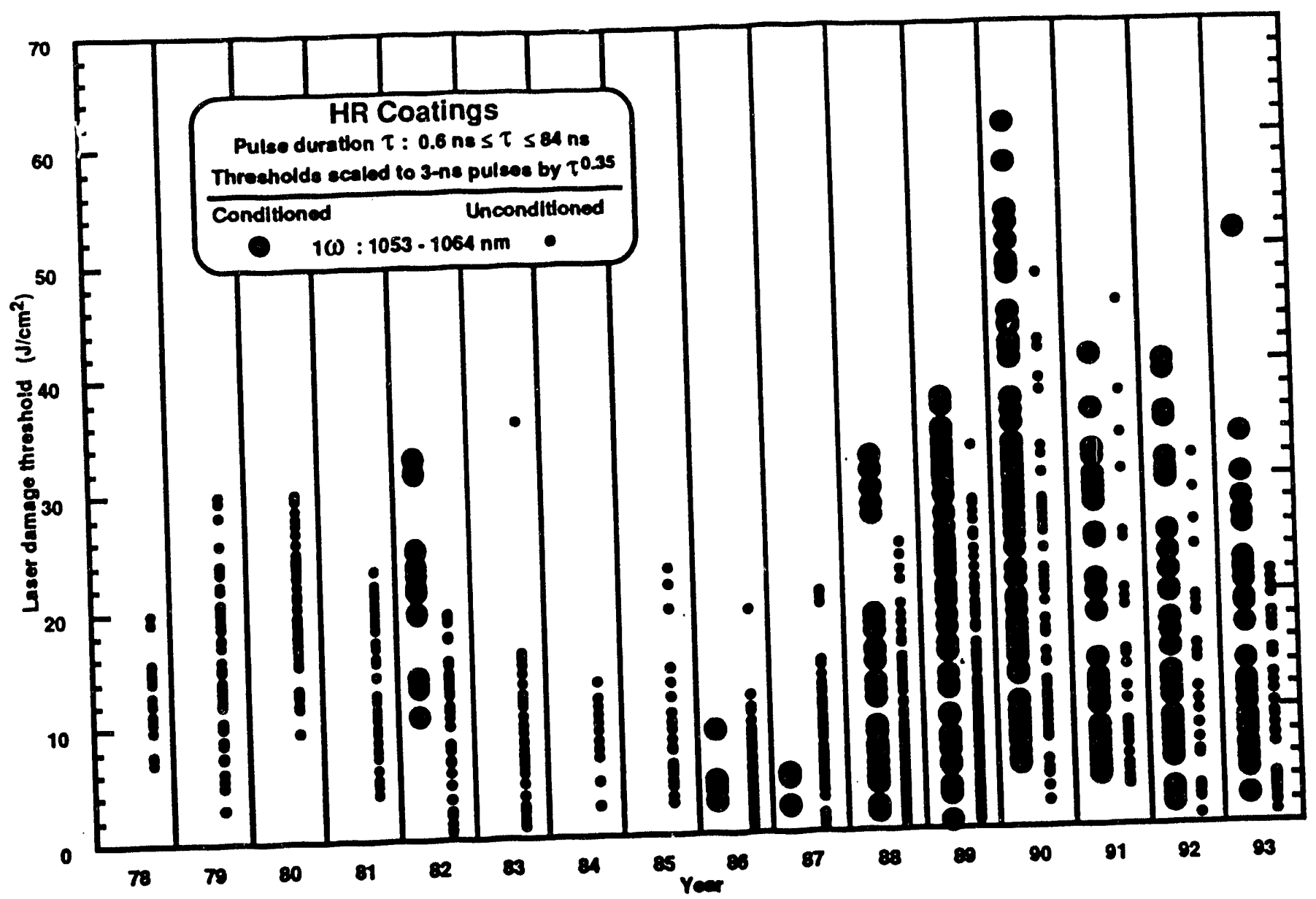

Fig. 4. Conditioned and unconditioned damage thresholds of all highly reflective (HR) coatings measured at 1064 $\mathrm{nm}(1 \omega)$, scaled to 3 -ns values by $\tau^{0.35}$.

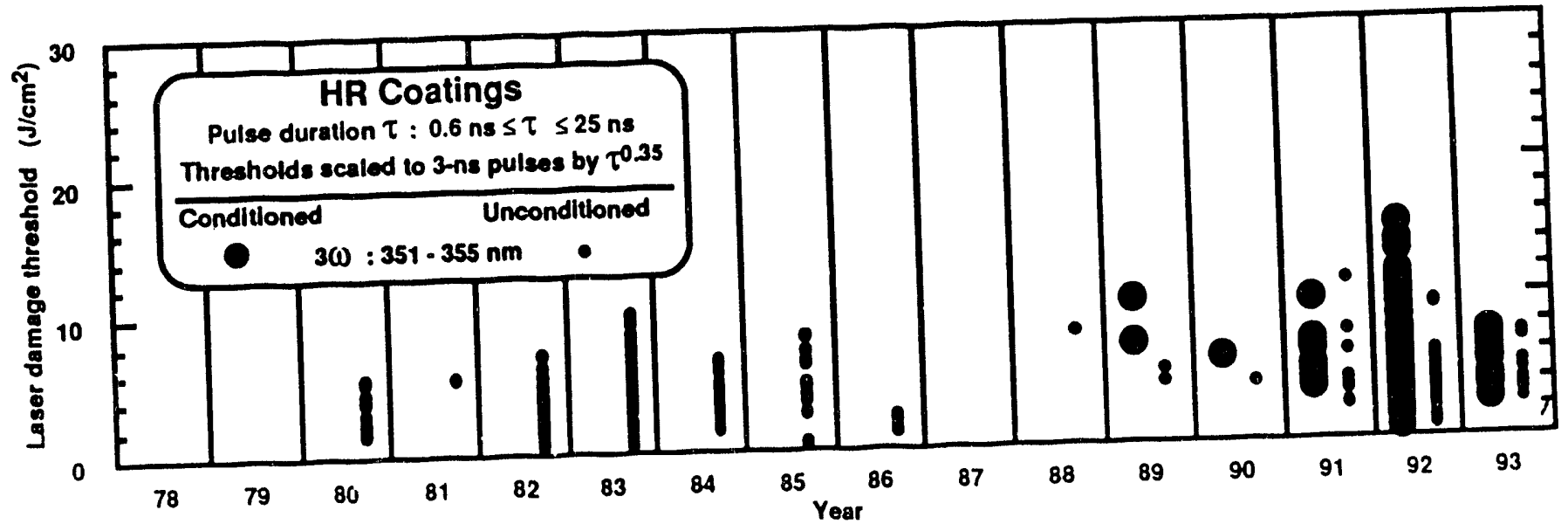

Fig. 5. Conditioned and unconditioned damage thresholds of all highly reflective (HR) coatings measured at 355 $\mathrm{nm}(3 \omega)$, scaled to 3 -ns values by $\overbrace{}^{0.35}$. 
improvements of their thresholds with conditioning. $28,29,30$ The threshold requirements of future laser systems necessitate that current defect-laden HR coatings need to be conditioned to comfortably survive high laser fluences. The preferable alternative would of course be to eliminate the defects altogether during the coating process. This has been under study at LLNL by a variety of techniques, including baffling and electrostatic repulsion, to reduce the effects of spatter. ${ }^{31}$ The spread in damage thresholds shown in Fig. 4 for the last few years has actually not changed much. The highest thresholds achieved in 1990 with the polished, undercoated, thick layers has not been duplicated by conventional e-beam coatings. However, it should also be noted that most of the low threshold HRs shown for recent years are not representative of routinely achievable good optics. These samples included further experiments with sputtered HRs, ion-assisted coatings, and vendor qualification tests. Experimental solgel HR coatings fabricated by spin coating or meniscus coating have not yet yielded cosmetically clean production-grade samples. ${ }^{14}$ However, they have shown encouraging signs of improving in cleanliness and thresholds, particularly with the use of PVA binders. 32

We expended the greatest amount of effort in almost a decade in addressing damage issues to $3 \omega$ HRs. Depending on the applicable scaling factors we have observed 3-ns thresholds approaching $15 \mathrm{~J} / \mathrm{cm}^{2}$. However, cosmetically clean coatings usually fell at half that level with little or no improvement attributable to conditioning. Moreover, because of the sensitive design and fabrication criteria for high-angle-of-incident $H R s\left(245^{\circ}\right)$, such mirrors typically have had even lower thresholds. The preferred high-index materials are still scandia and assorted fluorides as was the case in the early 1980 s for both $3 \omega$ and $4 \omega$ coating development. 18,33

\subsection{Polarizers}

Polarizers have become one of the more critical coating components in large-aperture laser systems. Fig. 6 shows all of the tests that we have conducted on polarizers at $1 \omega$, scaled to $3-n s$ values by $\tau^{0.35}$. We have conducted virtually no polarizer tests at the other harmonics since they are not employed in our large lasers. Polarizers present an added complication to those of HRs at high angles since they cannot simply be designed to sit somewhere near the middle of a broad reflection peak. They must, in fact lie near an edge so as to transmit most of the P-polarization while reflecting most of the S-polarization.

Between 1978 and 1988 we conducted a relatively small number of polarizer damage tests. Commercial vendors had little interest in devoting any significant resources in a relatively complex problem with less financial payback than HRs. Moreover, in those earlier years, polarizers were typically situated in low-fluence positions in the laser chain so that they did not represent a significant problem as far as damage was concerned.

However, beginning in 1989 to the present, we have engaged in a concerted effort to improve both the optical performance and damage resistance of e-beam-deposited, multi-layer polarizers. This work piggy-backed on to our HR coating efforts so that we concentrated primarily on hafnia/silica coatings with just a few tests on tantala/silica samples. Except for some low-threshold coatings, evaluated for potential coating suppliers, our polarizer research involved many samples from only a few commercial vendors. The thresholds therefore showed more consistency since only small perturbations were usually attempted in optimizing coating runs. This was particularly evident by the relative spreads of conditioned and unconditioned thresholds. As a whole, conditioning of nodular defects improved damage thresholds by a factor greater than $2 .{ }^{23}$ However, because of the sensitivity of coating designs at Brewster's-angle incidence, polarizers have not achieved thresholds as great as those of normal-incident HRs. This sensitivity was particularly noticeable for tests conducted in 1990. These samples, both experimental ones and production-run witnesses, showed a pronounced drop in thresholds from the previous year. Careful attention to the minimization of nodular defects during the coating runs has brought thresholds back up. However, we have not been 
able to completely achieve the high-threshold consistency of the 1989 coatings. Subsequent retests of these original samples verified that they did indeed have high thresholds and were not just subject to a possible change in calibration of the damage testing experiment.

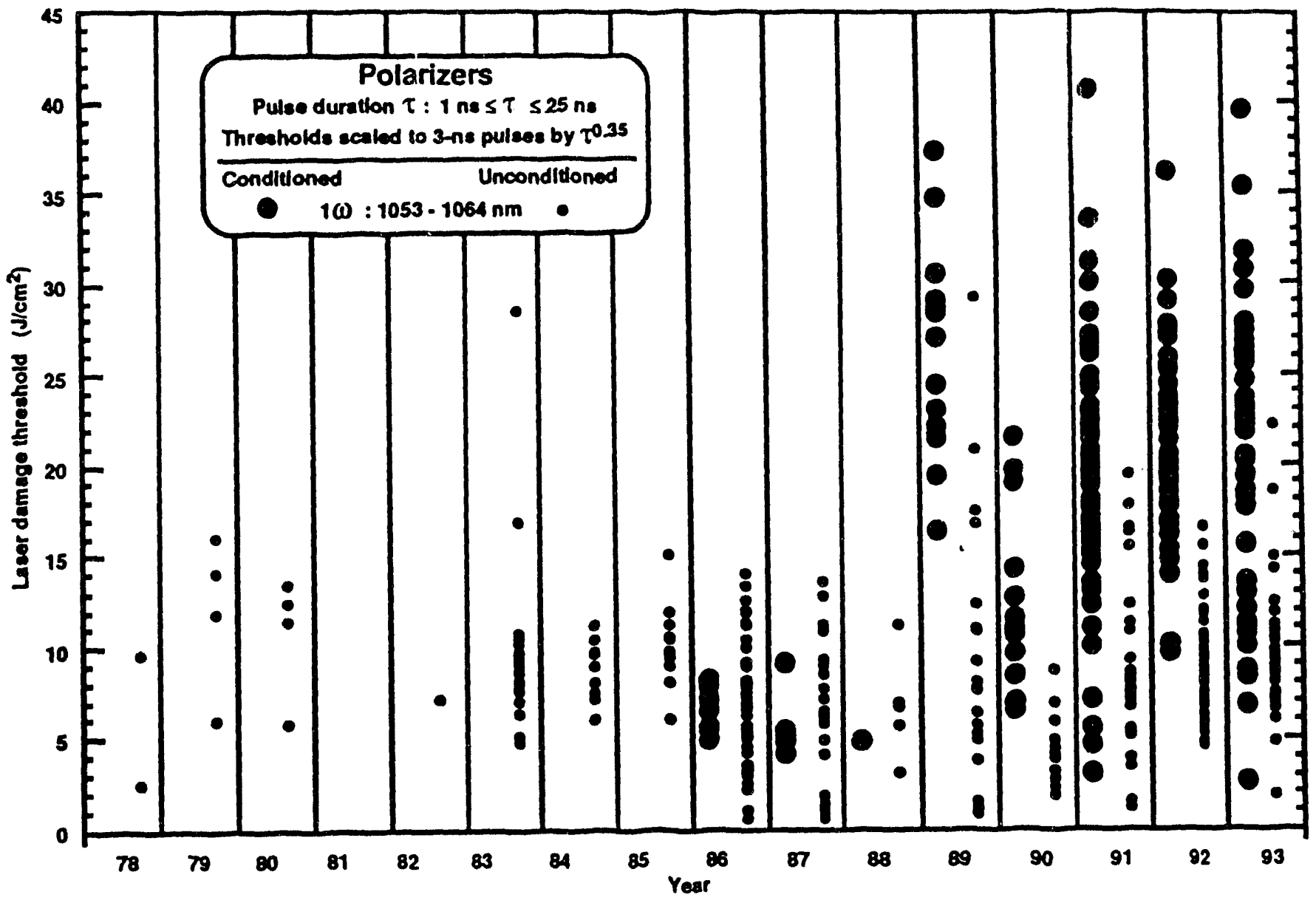

Fig. 6. Conditioned and unconditioned damage thresholds of all polarizers measured at $1064 \mathrm{~nm}(1 \omega)$, scaled to 3-ns values by $\tau^{0.35}$.

\subsection{KDP and KD*P crystals}

Over the span of 15 years we have conducted more damage tests on KDP and KD*P crystals than any other unique optic. Moreover, the actual data volume was made larger because (1) we have typically identified damage by its location at the front surface, rear surface, and within the bulk material, and (2) we routinely conducted both conditioned and unconditioned damage tests. Improvements in the diamond turning of the crystal surfaces and solgel AR coatings have resulted in relatively high surface-damage thresholds. Hence, the failure mechanism of recent samples usually stemmed from damage within the bulk material. Fig. 7 shows all of the conditioned and unconditioned threshold measurements that we have conducted on bulk material at $1 \omega$ and $3 \omega$ since 1986 . We have again scaled the thresholds to $3-n s$ values, but by a scaling factor of $\tau$ 0.5. The figure does not distinguish between KDP and $K D * P$.

Prior to 1988 the damage thresholds of KDP crystals varied considerably from sample to sample. These crystals typically had moderate to high densities of pre-existing bulk defects. The number of such visible defects usually 
increased with laser irradiation or grew larger with fractures on the order of several hundred $\mu \mathrm{n}$. We do not show any of the bulk threshold measurements prior to 1986 in Fig. 7. However, even in these early years, as noted above, we observed significant improvements in thresholds both by laser conditioning and thermal conditioning. $21,22,34$

From 1988 to the present we have observed steadily rising thresholds. This was attributable primarily to improved crystal-growing techniques employing ultrafiltration to produce crystals with bulk materials virtually free of any visible defects $25 \mu \mathrm{m}$ in size. 35 Fig. 7 shows that at $1 \omega$ conditioning of KDP improved the threshold by a factor of 2.1 over unconditioned values. 36 We observed even greater improvernent by thermally annealing KDP crystals at temperatures ranging from $135^{\circ} \mathrm{C}$ to $175^{\circ} \mathrm{C} .37 \mathrm{On}$ the other hand, some of the newest KDP crystals had such inherently high thresholds that they required no conditioning at all. At $3 \omega$ we did not observe improvements of the same degree as at $1 \omega$, both with laser and thermal conditioning. Nevertheless, KDP thresholds would still exceed large-laser requirements.

KD*P showed comparabie factors in improvement in $1 \omega$ thresholds with conditioning, but began at nominally $20 \%$ lower unconditioned threcholds. Thermal conditioning for $\mathrm{KD}{ }^{*} \mathrm{P}$ was more restrictive since the crystal undergoes a phase transition at about $130^{\circ} \mathrm{C}$ for $80 \%$ deuterated $\mathrm{KD} * \mathrm{P}$. Thus, we observed only marginal improvements in $1 \omega$ thresholds with low-temprrature thermal conditioning alone. At $3 \omega$ thermal conditioning to KD*P was essentially ineffective. For $\mathrm{KD}^{+} \mathrm{P}$ crystals that will be exposed to high-fluence, $3 \omega$, laser irradiation, the crystals will have to be baked for longer times and/or be laser conditioned with a full-area beam on a large laser system or be rastered in stages with a small test laser.

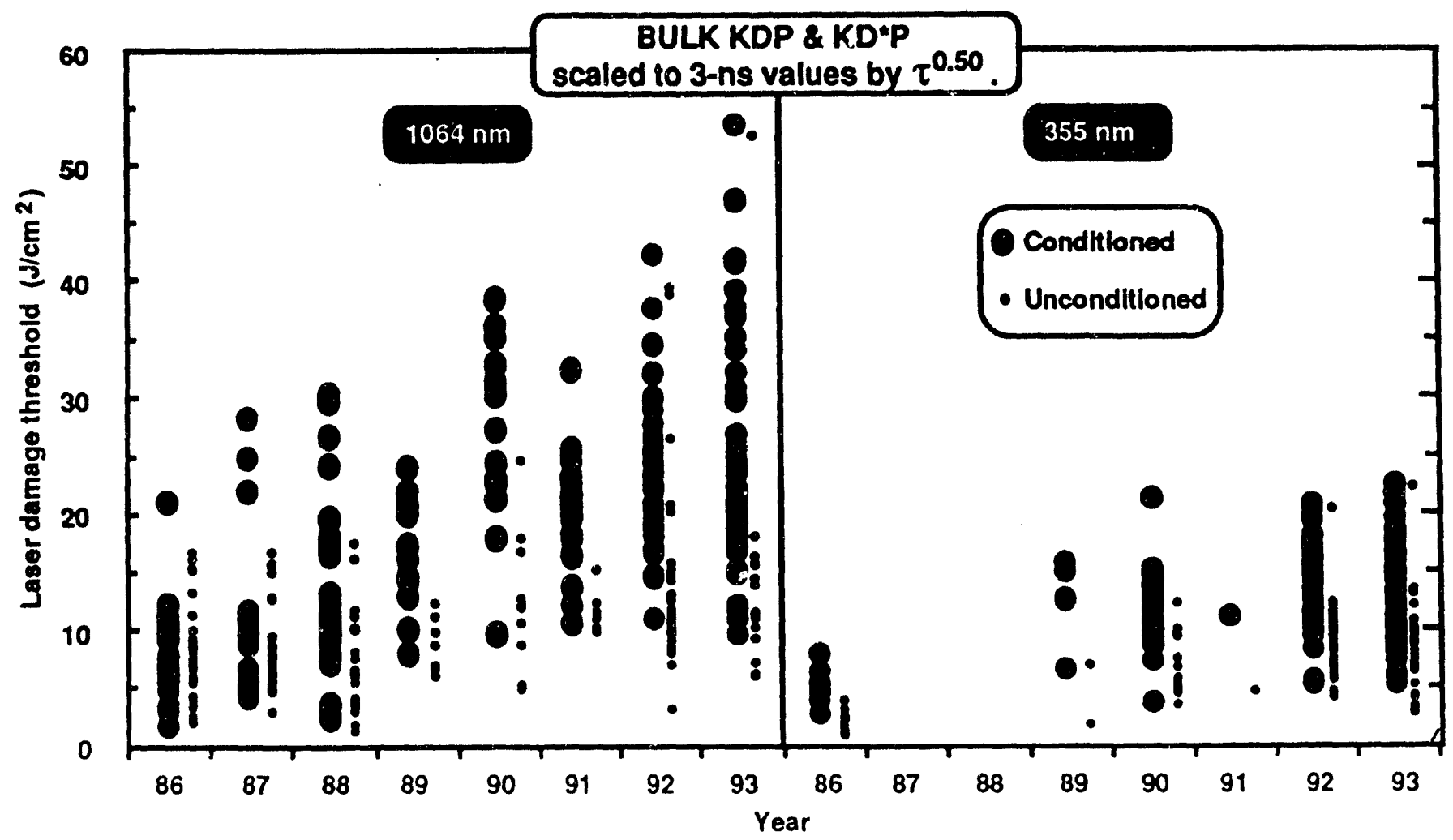

Fig. 7. Conditioned and unconditioned bulk damage thresholds of all KDP and KD*P crystals measured at 1064 $\mathrm{nm}(1 \omega)$ and $355 \mathrm{~nm}(3 \omega)$, scaled to 3 -ns values by $\tau^{0.5}$. 


\section{STATUS OF CONTEMPORARY AND FUTURE OPTICS}

L.LNL is currently engaged in developing a conceptual design for a NIF laser. Not only must the components for this laser meet strict optical requirements, but very often the actual design revolves around the damage thresholds of several critical elements. In Fig. 8 we show an early proposal for the conceptual design fluences of various optics required on NIF. These have been normalized to a scaled pulse duration of $4.8 \mathrm{~ns}$. The solid curves represent pulseduration scalings of $1 \omega$ (shaded) and $3 \omega$ (black) thresholds for each respective optic type. Only the $3 \omega$ threshold of KD P does not meet the strict interpretation of required damage threshold on NIF. However, as noted above, these are expected to improve with a combination of thermal and laser conditioning.

It should be noted that, not only are these thresholds based conservatively on the lowest measured value for an optic of recent vintage, but also often on a very strict interpretation of damage. Hence, a threshold has often been assigned based on individual damage pinpoints $\leq 10 \mu \mathrm{m}$ in size. Since most optics typically already have pre-existing
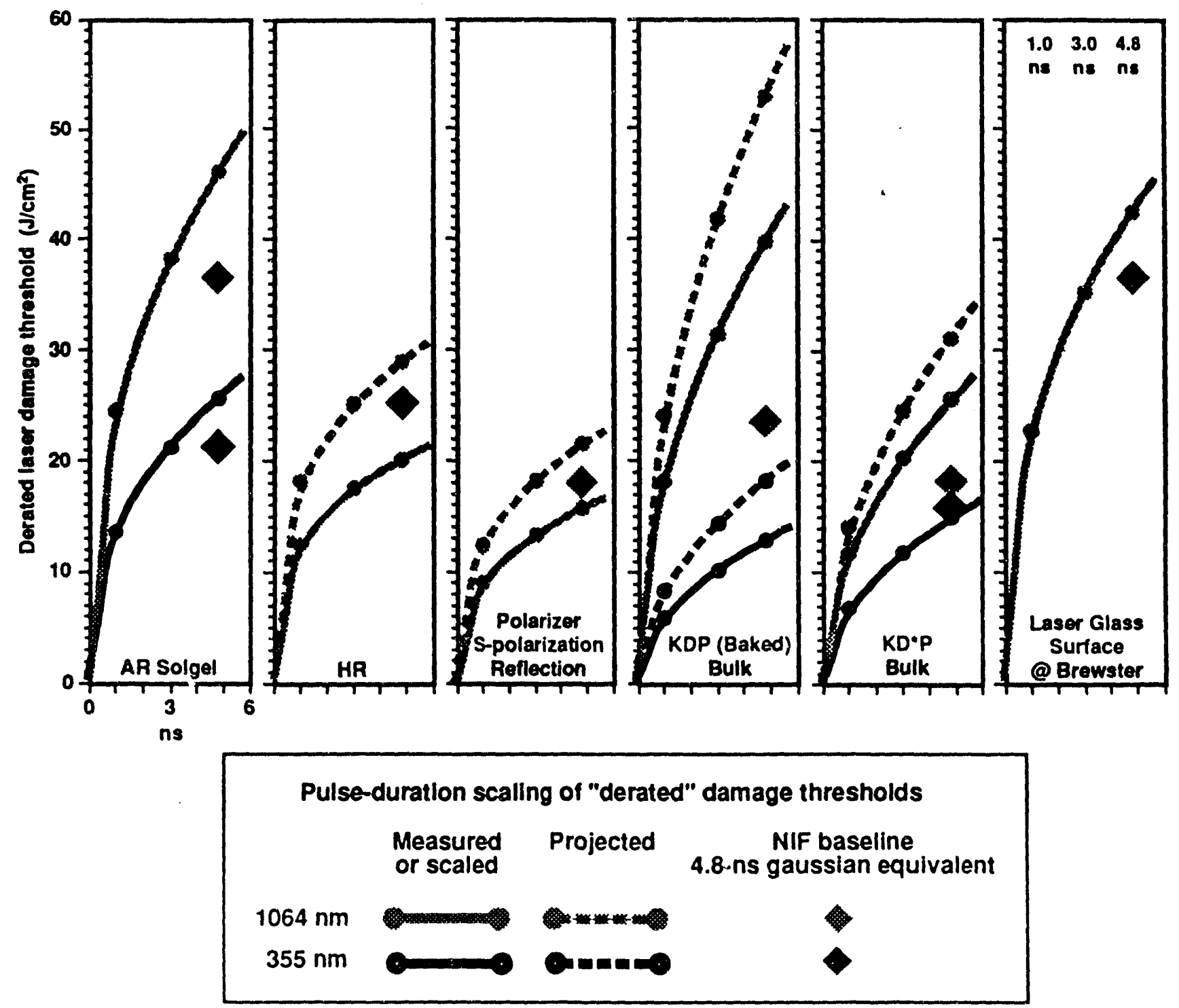

Fig. 8. Scaled damage thresholds and requirements at $1064 \mathrm{~nm}$ and $355 \mathrm{~nm}$ for crtical optical elements in a National Ignition Facility (NIF). 
defects of such dimensions, a few more would not actually impact the performance of the optic. By our strict definition of damage, every optic on the current Nova laser is damaged. The dashed lines in Fig. 8 represent thresholds that have already been obtained for many samples and (1) can realistically be expected to be obtained in the future for all optics, or (2) would exhibit such subtle damage morphology that the damage would not affect the laser performance. However, in our testing, we will continue to adhere to our strict definition of damage since we only test a relatively small area of a sample. We need to be confident that the test area or volume is always conservatively representative, not only of the entire sample as a whole, but also of other samples fabricated under comparable conditions.

All of the evidence from the past two years has led us to conclude that two important caveats must be adhered to in order to achieve consistently high threshold optics in large laser systems. Defects, whether they resided on substrates, were deposited during coating, were grown within crystals, or were generated during subsequent handling and cleaning must be kept to an absolute minimum. Quality assurance must be in force throughout the fabrication, shipping, cleaning, installation and handling processes to guarantee that such high standards of cleanliness in laser optics are never compromised.

\section{ACKNOWLEDGMENTS}

During the past fifteen years a great number of people have made important contributions to the materials development and laser damage work of the ICF program at LLNL. The authors wish to acknowledge in particular the devoted efforts of their colleagues Dave Milam and Ted Hildum.

This work was performed under the auspices of the U. S. Department of Energy by Lawrence Livermore National Laboratory under Contract No. W-7405-ENG-48.

\section{REFERENCES}

1. F. Rainer, E. A. Hildum, and D. Milam, "Database of Average-Power Damage Thresholds at 1064 nm," LaserInduced Damage in Optical Materials: 1987, Nat. Inst. Std. \& Tech. (U. S.) Spec. Publ. 756, pp. 410-418, October 1987.

2. F. Rainer, R.P. Gonzales, and A. J. Morgan, "Laser Damage Database at $1064 \mathrm{~nm}$," Laser-Induced Damage in Optical Materials: 1989, Nat. Inst. Std. \& Tech. (U. S.) Spec. Publ. 801, pp. 58-73, October 1989.

3. F. Rainer, L. J. Atherton, J. H. Campbell, F. P. De Marco, M. R. Kozlowski, A. J. Morgan, and M. C. Staggs, "FourHarmonic Database of Laser-Damage Testing," Laser-Induced Damage in Optical Materials: 1991, SPIE Vol.1624, pp. 116-127, October 1991.

4. A. J. Morgan, F. Rainer, F. P. De Marco, R. P. Gonzales, M. R. Kozlowski, and M. C. Staggs, "Expanded Damage Test Facilities at LLNL," Laser-Induced Damage in Optical Materials: 1989, Nat. Inst. Std. \& Tech. (U. S.) Spec. Publ. 801, pp. 47-57, October 1989.

5. W.H. Lowdermilk, D. Milam, and F. Rainer, "Damage to Coatings and Surfaces by $1.06 \mu \mathrm{m}$ Pulses," Laser-Induced Damage in Optical Materials: 1979, Nat. Bur. Std. (U. S.) Spec. Publ. 568, pp. 391-403, October 1979.

6. T. Tuttle Hart, C. K. Carniglia, F. Rainer, and M. C. Staggs, "Recent Damage Results for Antireflection Coatings, at 355 nm," Laser-Induced Damage in Optical Materials: 1983, Nat. Bur. Std. (U. S.) Spec. Publ. 688, pp. 340-346, October 1983.

7. C. K Carniglia, J. H. Apfel, G. B. Carrier, and D. Milam, "The Investigation of Effects of a Barrier Layer on Damage to $1.064 \mu$ AR Coatings," Laser-Induced Damage in Optical Materials: 1978, Nat. Bur. Std. (U. S.) Spec. Publ. 541, pp. 218-225, October 1978. 
-13 -

8. W.H. Lowdermilk and S. P.Mukherjee, "Graded-Index Antireflective Coatings for High Power Lasers Deposited by the Sol-Gel Process," Laser-Induced Damage in Optical Materials: 1981, Nat. Bur. Std. (U. S.) Spec. Publ. 638, pp. 432-438, October 1981.

9. J. E. Swain, W. H. Lowdermilk, and D. Milam, "Raising the Surface Damage Threshold of Neutral Solution Processed BK-7 by Pulsed Laser Irradiation," Laser-Induced Damage in Optical Materials: 1982, Nat. Bur. Std. (U. S.) Spec. Publ. 669, pp. 292-295, October 1982.

10. W. H. Lowdermilk, J. G. Wilder, N. J. Brown, C. A. Gunderson, D. Milam, and M. C. Staggs, "Laser Damage in Porous-Silica Antireflection Films," Laser-Induced Damage in Optical Materials: 1983, Nat. Bur. Std. (U. S.) Spec. Publ. 688, pp. 372-377, October 1983.

11. I. M. Thomas, J. G. Wilder, W. H. Lowdermilk, and M. C. Staggs, "High Damage Threshold Porous Silica Antireflective Coating," Laser-Induced Damage in Optical Materials: 1984, Nat. Bur. Std. (U. S.) Spec. Publ. 727, pp. 205-210, October 1984.

12. D. Milam, I. M. Thomas, C. Weinzapfel, and J.G. Wilder, "Pulse Duration Dependence of 1064-nm Laser Diumage Thresholds of Porous Silica Antireflection Coatings on Fused Silica Substrates," Laser-Induced Damage in 'Jptical Materials: 1984, Nat. Bur. Std. (U. S.) Spec. Publ. 727, pp. 211-216, October 1984.

13. I. M. Thomas, "Two Layer Broadband AR Coating," Laser-Induced Damage in Optical Materials: 1988, Nat. Inst. Std. \& Tech. (U. S.) Spec. Publ. 775, pp. 265, October 1988.

14. J. A. Britten and I. M. Thomas, "Sol-gel Metal Oxide and Metal Oxide/Polymer Multilayers Applied by Meniscus Coating," Laser-Induced Damage in Optical Materials: 1993, to be published these proceedings.

15. I. M. Thomas and J. H. Campbell, "A Novel Perfluorinated AR and Protective Coating for KDP and Other Optical Materials," Laser-Induced Damage in Optical Materials: 1990, SPIE Vol. 1441, pp. 294-303, October 1990.

16. R. Chow, M. K. Spragge, G. E. Loomis, I. M. Thomas, F. Rainer, R. Wand, and M. R. Kozlowski, "High Damage Threshold Anti-Reflectors by Physical Vapor Deposited Amorphous Fluoropolymer," Laser-Induced Damage in Optical Materials: 1993, to be published these proceedings.

17. I. M. Thomas, "Sol-gel Coatings for High Power Laser Optics - Past, Present and Future," Laser-Induced Damage in Optical Materials: 1993, to be published these proceedings.

18. C. K. Carniglia, T. Tuttle Hart, F. Rainer, and M. C. Staggs, "Recent Damage Results on High Reflector Coatings at 355 nm," Laser-Induced Damage in Optical Materials: 1983, Nat. Bur. Std. (U. S.) Spec. Publ. 688, pp. 347-353, October 1983.

19. C. K. Carniglia, T. Tuttle Hart, and M. C. Staggs, "Effects of Overcoats on 355-nm Reflectors," Luser-Induced Damage in Optical Materials: 1984, Nat. Bur. Std. (U. S.) Spec. Publ. 727, pp. 285-290, October 1984.

20. C. K Carniglia, J.H. Apfel, T. H. Allen, T. A. Tuttle, W. H. Lowdermilk, D. Milam, and F. Rainer, "Recent Damage Results on Silica/Titania Reflectors at 1 Micron," Laser-Induced Damage in Optical Materials: 1979, Nat. Bur. Std. (U. S.) Spec. Publ. 568, pp. 377-390, October 1979.

21. J. E. Swain, S. E. Stokowski, D. Milam, and F. Rainer, "Improving the Bulk Laser-Damage Resistance of KDP by Baking and Pulsed Laser Irradiation," Laser-Induced Damage in Optical Materials: 1981, Nat. Bur. Std. (U. S.) Spec. Publ. 638, pp. 119-128, October 1981.

22. M. C. Staggs and F. Rainer, "Damage Thresholds of Fused Silica, Plastics and KDP Crystals Measured with 0.6ns 355-nm Pulses," Laser-Induced Damage in Optical Materials: 1983, Nat. Bur. Std. (U. S.) Spec. Publ. 688, pp. 84-90, October 1983. 
23. C. R. Wolfe, M. R. Kozlowski, J. H. Campbell, F. Rainer, A. J. Morgan, and R. P. Gonzales, "Laser Conditioning of Optical Thin Films," Laser-Induced Damage in Optical Materials: 1989, Nat. Inst. Std. E Tech. (U. S.) Spec. Publ. 801, pp. 360-375, October 1989.

24. M.R. Kozlowski, C. R. Wolfe, M. C.Staggs, and J.H. Campbell, "Large Area Laser Conditioning of Dielectric Thin Film Mirrors," Laser-Induced Damage in Optical Materials: 1989, Nat. Inst. Std. \& Tech. (U. S.) Spec. Publ. 801, pp. 376390, October 1989.

25. M. C. Staggs, M. Balooch, M. R. Kozlowski, and W. J. Siekhaus "In Situ Atomic Force Microscopy of Laser Conditioned and Laser-Damaged $\mathrm{HFO}_{2} / \mathrm{SiO}_{2}$ Dielectric Mirror Coatings," Laser-Induced Damage in Optical Materials: 1991, SPIE Vol. 1624, Pp. 375-385, October 1991.

26. I.M. Thomas, J. G. Wilder, and R.P. Gonzales, "HRCoatings Prepared from Colloidal Suspensions," Laser-Induced Damage in Optical Materials: 1987, Nat. Inst. Std. \& Tech. (U. S.) Spec. Publ. 756, pp. 286-289, October 1987.

27. F. Rainer, F. P. De Marco, J. T. Hunt, A. J. Morgan, L. P. Mott, F. Marcelja, and M. R. Greenberg, "High Threshold HR Coatings at 1064 nm," Laser-Induced Damage in Optical Materials: 1990, SPIE Vol. 1441, pp. 247-254, October 1990.

28. M. C. Staggs, M. R. Kozlowski, W. J. Siekhaus, and M. Balooch, “Correlation of Damage and Surface Geometry of Nodular Defects in HR Coatings as Determined by In-Situ Atomic Force Microscopy," Laser-Induced Damage in Optical Materials: 1992, SPIE Vol. 1848 pp. 234-242, October 1992.

29. M. R. Kozlowski and R. Chow, "The Role of Defects in Laser Damage of Multilayer Coatings," Laser-Induced Damage in Optical Materials: 1993, to be published these proceedings.

30. M. D. Miller, R. Chow, G. E. Loomis, and F. Rainer, "Electrostatic Reduction of Particulates for Laser Resistant Hafnia Coatings," Laser-Induced Damage in Optical Materials: 1993, to be published these proceedings.

31. R. J. Tench and M. R. Kozlowski, "Characterization of Defect Geometries in Multilayer Optical Coatings," LaserInduced Damage in Optical Materials: 1993, to be published these proceedings.

32. I. M. Thomas, "Effect of Binders on the Damage Threshold and Refractive Index of Coatings Prepared from Colloidal Suspensions," Laser-Induced Damage in Optical Materials: 1992, SPIE Vol.1848 pp. 281-289, October 1992.

33. F. Rainer, W. H. Lowdermilk, D. Milam, C. K. Carniglia, T. Tuttle Hart, and T. L. Lichtenstein, "Damage Thresholds of Thin Film Materials and High Reflectors at 248nm," Laser-Induced Damage in Optical Materials: 1982, Nat. Bur. Std. (U. S.) Spec. Publ. 669, pp. 274-281, October 1982.

34. R. P. Gonzales, M. C. Staggs, M. F. Singleton, D. George, C, L. Weinzapfel, and S. Weinzapfel, "Variation with Laser Pulse Duration of the Thresholds at 350-nm and 1064-nm for Bulk Damage in Crystals of KDP," LaserInduced Damage in Optical Materials: 1986, Nat. Inst. Std. \& Tech. (U. S.) Spec. Publ. 752, p. 206, October 1986.

35. K. E. Montgomery and F. P. Milanovich, "High-Laser-Damage-Threshold Potassium Dihydrogen Phosphate Crystals," J. Appl. Phys. 68 (8), pp. 3979-3982, 15 October 1990.

36. F. Rainer, L. J. Atherton, and J. J. De Yoreo, "Laser Damage to Production- and Research-Grade KDP Crystals," Laser-Induced Damage in Optical Materials: 1992, SPIE Vol. 1848 pp. 46-58, October 1992.

37. L. J. Atherton, F. Rainer, J. J. De Yoreo, I. M. Thomas, N. Zaitseva, and F. P. De Marco "Thermal and Laser Conditioning of Production and Rapid-Growth KDP and KD4P Crystals," Laser-Induced Damage in Optical Materials: 1993, to be published these proceedings. 


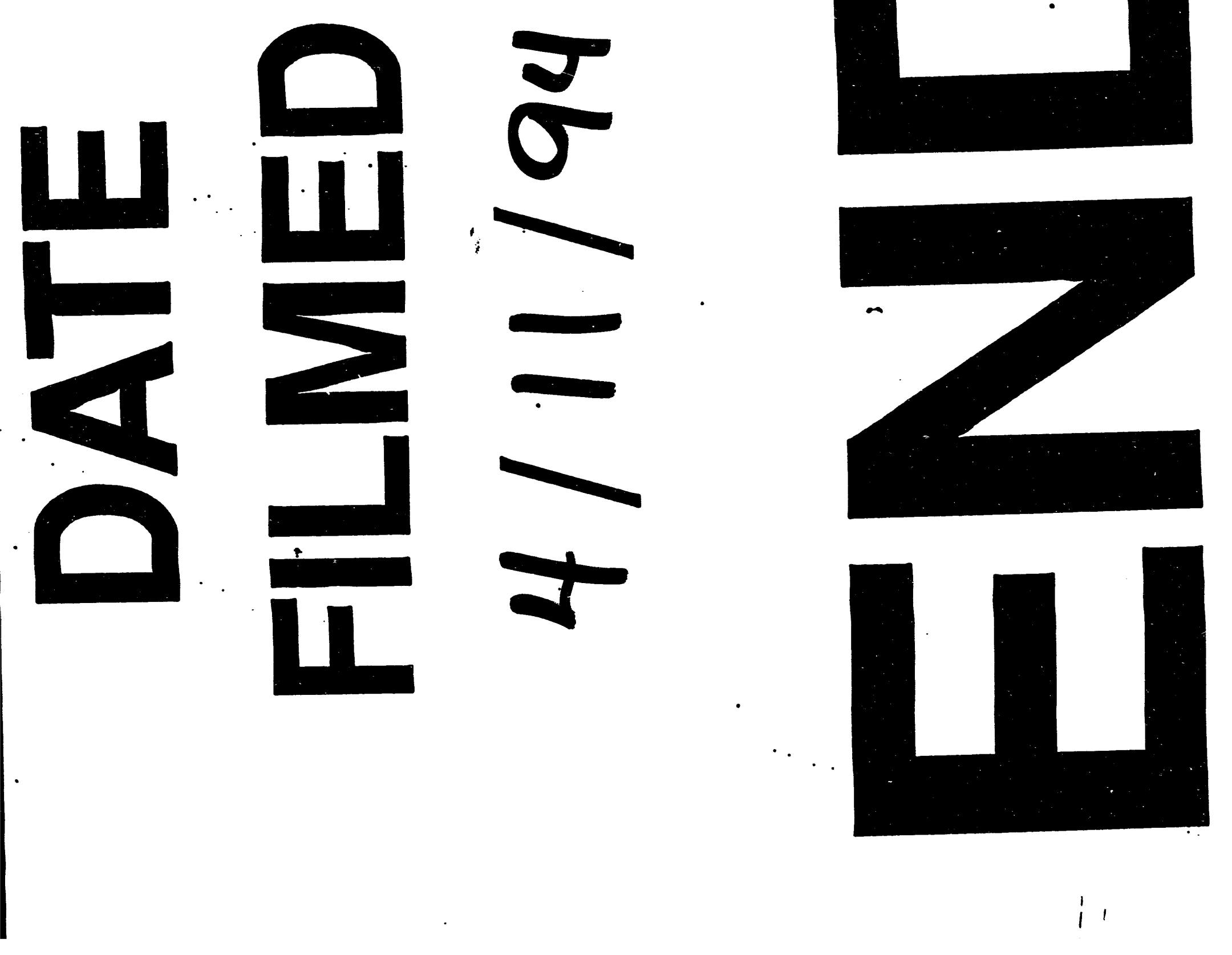


